\title{
Big-C Research - The Big Challenge? Reflections from Research into Eminent Creativity in the Light of the Investment Theory of Creativity*
}

\author{
Izabela Lebuda \\ Academy of Special Education, Poland \\ E-mail address: izalebuda@gmail.com
}

\section{ARTICLE INFO}

\section{Keywords:}

Eminent creativity

Investment theory of creativity

Methodology

\author{
Article history: \\ Received 28 February 2014 \\ Received in revised form 6 June 2014 \\ Accepted 6 June 2014 \\ ISSN: \\ DOI: 10.15290/ctra.2014.01.01.03
}

\begin{abstract}
A B STRACT
In this article, based on personal experience, I present the challenges, associated with the study of eminent creativity (Big-C creativity) in the light of the investment theory of creativity (Sternberg \& Lubart, 1991, 1996). I point out the difficulties and costs (obstacles specific to this area of research) that the researcher needs to take into consideration and I try to determine the potential profits (in the form of publications in leading journals) associated with the decision to explore this field. Reflections and impressions related to conducting a research project about eminent creativity are complemented by statements from professional art critics, renowned Polish artists, excerpts from correspondence with prominent artists, their managers, and researchers of eminent creativity, and a comparison of publications devoted to potential and realized creativity in four leading creativity journals. Based on the analyses of this diverse information, studying eminent creativity would seem to be a risky investment, requiring specific research efforts while giving uncertain profits in the form of publication of the results.
\end{abstract}

\section{INTRODUCTION}

The present text is unusual in relation to articles that are usually found in scientific journals. Instead of presenting a literature review, research results or a new theoretical model, I put forward my thoughts concerning studying eminent creativity. The argument presented is based on my research experience, which I discuss with reference to the investment theory of creativity (Sternberg \& Lubart, 1991). This approach focuses on the role of buying ideas low and selling them high, thus the choice of a field, subfield or theme, where one meets little competition and which is not highly time- or energy-consuming, but there is an increasing demand for products of a given area (see also Rubenson \& Runco, 1992). The investment theory in creativity is usually applied to explain the problems associated with studying eminent creativity. The regularities that it describes, however, are

\footnotetext{
*This study was supported by a grant DEC-2011/03/N/HS6/05137 from the National Science Centre, Poland. I thank Maciej Karwowski for his comments.
} 
a good starting point for the interpretation of the phenomena associated with other levels of creativity as well (Kaufman, 2009), especially professional creativity (Pro-c creativity).

The idea for presenting the article in this way emerged during a graduate class, where I advised students on choosing the subject of their work by suggesting that they should try to buy low and sell high (Sternberg \& Lubart, 1991). In order to present this metaphor more vividly, I started looking for an example by going through all my research projects and it occurred to me that one of them may actually be an anti-example, in that it requires considerable investment and the profit is very uncertain.

For over two years, I have been conducting a project devoted to identifying the roles that educational experiences and significant others play in a creator's life, on the path towards eminent creativity in chosen fields. During this project, I have made numerous investments, which, in comparison to other projects that I lead or participate in, are unusual and demanding. They could be measured in hours spent organising and conducting research, in the hundreds of kilometres travelling to meet respondents at a place of their choosing, or in the thousands of miles travelling to Claremont Graduate University, which I visited in order to deepen my knowledge and improve my skills in the area of creativity research under the wings of Mihaly Csikszentmihalyi (1997).

The cost of the topics chosen goes beyond the time devoted, travelled in kilometres and miles, and the need to familiarise myself with the achievements and methodology typical for this subfield. The cost of research on eminent creativity is associated with undertaking a number of arbitrary, thus risky, decisions, which do not guarantee profits i.e. exposure of the results to a wider audience. Every research project requires involvement, and the author does not know how interested other researchers are likely to be in the results. In this article, I will only focus on the challenges specific to the study of eminent creativity.

\section{CHALLENGES IN RESEARCH ON EMINENT CREATIVITY}

\section{Challenge 1. Participant Selection}

The first investment decision that needs to be made by the researcher is the selection of the study participants i.e. convincing first the internal university authorities, then external organisations funding grants, and ultimately the readers of publications, that the creators elected deserve the title 'eminent' (see Barsalou \& Prinz, 1997; Boden, 1996; Csikszentmihalyi, 1997; Kaufman \& Beghetto, 2009; Richards, 1990; Simonton, 2010). This problem is particularly pronounced when presenting the results of studies to an intercultural arena, in the broader environment in which what are deemed to be creative, eminent works in one country or region, within another may be completely unknown (Stein, 1953; 
see also Boldface-C Creativity, Simonton, 2010, p. 175). Apart from the cultural differences in the evaluation of eminent creativity (Niu \& Sternberg, 2006; Rudowicz, 2003), the researcher faces the need to distinguish between professional level creativity (Pro-c) and eminent level creativity (Big-C) (Kaufman \& Beghetto, 2009). A popular method is to appeal to the proof of social judgment and thus to public opinion. However, this method is not perfectly reliable because the judgment of a person not involved in the subject of creativity is, to a large extent, affected by frequency of contact with the information and its distinctiveness (Kahneman, Slovic \& Tversky, 1982). Thus it is easy to blur the boundaries between eminent creativity and popularity, as the latter depends hugely on the field represented - the actor has a higher chance of becoming popular than the director, the director than the editor, and all of them have a greater chance of popularity than scientists. Doubts of the researcher-investor about these criteria are enforced by the results of an online survey (Karwowski \& Lebuda, will be published in 2015), in which adult Poles $(N=302)$ were asked to indicate the most creative living Pole. Nearly every third person (29.4\%) was unable to identify an individual of this Kind or thought that no one deserved the title, $3.6 \%$ of respondents, despite the instructions, chose an egalitarian understanding of the term and pointed to themselves, a member of their family, or gave the answer: 'everyone'. A small proportion of the respondents (2.3\%) suggested deceased creators: Boleslaw Prus, Marie Sklodowska-Currie, Mikolaj Kopernik, Adam Mickiewicz, Fryderyk Chopin, and even the Dalai Lama appeared among the suggestions for living Poles (0.3\%). The most popular choices among living people were: Lech Walesa $(5.0 \%)$ and Andrzej Wajda (4.0\%). Interestingly, social activists (Jerzy Owsiak and Janina Ochojska) were mentioned by $3.0 \%$ of respondents (see McGonigal, 2010), and 15.3\% chose a politician as a creator (see also Gardner, 1993; Simonton, 1994). Further comments from respondents showed that eminent creativity in politics does not always have a positive association (being even extremely negative or malevolent, see Cropley, Kaufman, Cropley \& Runco, 2010). Among the long list of names, most got single votes. The large variety of results, the low indices obtained by the person most frequently indicated and the high percentage of 'do not know' answers, confirm the problems of respondents with identification of an eminent creator (Baer, 1998, 2010; Baer \& Kaufman, 2005).

An alternative solution is to ask experts judged as competent in a given field to complete a survey (Amabile, 1982). However, representatives from this domain usually have even more strongly varied opinions than laymen (Getzels \& Csikszentmihalyi,1969). Opinions from the field (Csikszentmihalyi, 1997) largely depend on affiliation with certain trends and desired aesthetics (Eysenck, 1995). It is also conceivable that the evaluated 
product (or person through the prism of achievements) can be so original, that the recipients, even professionals, will not be able to understand and appreciate them (Simonton, 1984). During interviews with two professional music critics and one film critic, I asked about the criteria for assessing creativity. They emphasised two main aspects-the recipient's (specialist's) personal feelings and novelty, not only in a social context, but also a personal one, including the personal transgressions of the author i.e. change of direction in his or her career, which is regarded as evidence of continuous study and efforts to expand their creative developments. The professional critics stressed that art criticism is very subjective:

"I cannot say that this is good, I like it, yes. I favour constructive criticism, I write only about what is valuable to me, I ignore what does not fit my sensibility. I am glad that there are people who want to listen to my opinion and want to use it as direction, it is a privilege and responsibility to be an advisor in an area where there is no clear measure of good and bad."

Determination of the measure in assessing eminent creativity is another problem. Scales used for such assessments often do not match artistic or scientific realities. According to conversations with creators, this is particularly evident in the teaching of professional creativity-in the words of a film director:

"The fact - let's say - that art is graded like in a primary school, someone got A or F, the idea itself is absurd. I'm curious how my lecturers would assess The Godfather or Four Tank Men and a Dog? The film is bad (did not pass,) or good (passed), or exceptional (prize, festivals - priceless for a student)."

The researcher-investor must be aware of the fact that the assessment of creativity is influenced by characteristics unrelated to the quality of the work(s) (Kasof, 1995). Attributions, constructed on the basis of non-artistic or non-scientific characteristics, interfere with assessments made by the layman (Lebuda \& Karwowski, 2013), and those made by professionals who are subject to different types of illusions, for example, evaluating and shaping the image of the creator based on his/her external characteristics. One Polish writer interviewed, deems this a sign of a lack of competence in the case of critics and says:

"When it comes to image, people think it is important that I dress weird, but I think it's completely unrelated to writing. It just irritates me in the sense that no one writes about the way in which Marcin Swietlicki dresses, but it is also a matter of Polish criticism, which is not of a high standard and is moving in the direction of some sort of tabloidization."

Selection of appropriate criteria for assessing levels of creativity is one of the biggest in- 
vestment risks and challenges that the researcher faces. Dean Keith Simonton, in e-mail correspondence described it this way:

"It's hard to get samples of truly eminent creators - the creative geniuses-without using historical and biographical data. Yet the latter do not allow the application of psychometric and interview techniques. Everybody agrees that Albert Einstein was highly creative, but how can such greats be best studied retrospectively?"

Rating excellence is easier in the case of deceased artists whose achievements are completed and easy to access, the investigator is limited by the confidentiality of information to a lesser extent, and it is also easier to establish the criteria for excellence, especially if enough time has passed since their death, which allows the researcher, for example, to determine the number of references to the author's works by people in the field he worked in and more widely. Indeed, in the study mentioned above (Karwowski \& Lebuda, will be published in 2015), participants agreed on the choice of eminent deceased Polish creators to a much greater extent than when making nominations from among those still living; in this case only $9.4 \%$ of respondents answered 'I do not know' or 'no one'. Indications were also to a greater extent consistent-every fourth respondent chose John Paul II as an eminent creator (21.9\%), and this choice was followed by: Marie Sklodowska-Curie (13.9\%), Mikolaj Kopernik (10.3\%), Wislawa Szymborska (8.3\%), and Fryderyk Chopin $(4.9 \%)$. Even though, in the case of the achievements of the deceased, researchers can easily operationalise criteria for eminent creativity, such analysis has an essential restriction, particularly in the case of application projects whose aim is to formulate conditions for practical action.

\section{Challenge 2. Reaching out to Participants and Convincing Them to Take Part in the Study}

In the case study on eminent creativity in a personal context, when it comes to living creators, a lot of effort was required to contact potential participants and obtain their consent to participate in the study. In the academic environment, researchers can contact creative individuals through their website and expect that they will understand the difficulties with conducting such a study and be willing to cooperate. Among the e-mails I sent to Nobel Prize winners, whose contact details I found on their websites, the majority answered in person or through their assistants. Even where people were unable to fully commit to the project at the time, wherever possible, they tried to support the research. For example, the assistant of one of the 2012 Nobel Prize winners, in reply to my request answered: "The professor has a lot of obligations, please, select one or two most important questions and we will try to reply as soon as possible." It is considerably harder to contact eminent artists, who are often represented by their managers or for whom the realities of sci- 
entific research are distant. Here is the e-mail reply from the media manager of one of the Polish musicians I attempted to contact: 'The interview on the new album will be published in <Title of the journal>, please, use the text and send your essay for approval via e-mail'.

Successfully contacting respondents and eminent artists does not ensure success and is not a guarantee of consent to participate in research. One of the obstacles is represented by the specific, often fixed creative mindsets (Dweck, 2006; Karwowski, 2013) of artists and academics. I selected three such types of judgments on the basis of conversations conducted. First, a romantic belief in the mystical nature of creativity and thus the impossibility of studying or measuring it is illustrated by the opinion of a Polish film director:

"It is very difficult not to fall into banality. And on the other hand, one should talk about it honestly. I believe it is .... I believe, so it is a question of belief - that it is not completely coming from me. I believe, that I am a transmitter and that on my 'purity' depends the quality of later works of art. I have a chance, I happen to have a chance to be connected, somehow, to the territory .... I have got access to a territory, from which it can be pulled down to Earth. And then, the most important things are created things that shape and change me, and therefore change the environment that receives this creation. And it is a great privilege, a great chance. It happens very rarely, of course, it is usually very difficult to hold on to this state. And then, when it is not there, the only things left are: cleverness, skills and craft. However, I think that we may speak about some sort of revelations. I felt, quite distinctly, when something important was about to be created and usually I was right. I had a feeling of connection with some territory that cannot be described, cannot be transmitted .... and one should not look inside there and try to specify it any further."

The second group of judgments is related to the identity of the creator and the conviction that every creator is different, so you should not seek to generalise. The following is from a conversation with a famous performer:

"It seems to me that I am such a lunatic, I mean, different from the rest of the artists, that I cannot be assigned to any trend, so I do not know if what I say would be helpful. .... that is the way with artists, everyone is different and it cannot be interlinked, as you suggested, 'problematically".

The final conviction, which made it difficult to encourage eminent artists to participate in the study, was the belief that creativity is the result of an innate talent/gift, therefore the study of creativity cannot lead to important conclusions for educational or therapeutic practice-a man is or is not born a creator. According to an artist and long-time educator: 
'I cannot teach anyone talent. I am not getting involved with ideas unless they go beyond the ethical sphere'.

Creators invited to participate in the study were often concerned about their image, they were afraid of testing, of losing their privacy. In conversations, they emphasised that art is their preferred form of expression and communication, asserting that talking about it is embarrassing, suggesting it interferes with their private sphere. Some artists did not want to talk about their work or themselves, because, as stated by a famous musician: 'it is not something unusual, it is years of craft, everyday work, but for me it is better if people see inside me an artist .... who drinks, is crazy about women and creates under inspiration and for sure, is in pain at the source'. Concerns about self-image bind to the subsequent problem of deliberate distortion of information, selective choice of data in order to confirm the creativity myth, sometimes not just the myth of the creator but of the whole creative field.

\section{Challenge 3. Choice of Study Method}

Participating creators were particularly concerned about quantitative measurements, considering them more difficult to consciously control, and consequently they thought that they gave a better chance of getting negative evaluative results. Creators, especially those who are popular, feared revealing individual results to the public. This is probably the reason why, studies of eminent creativity, which use questionnaires or tests, are so rare (Mroz, 2008). Published studies do not use instruments to measure creative ability because such tests or questionnaires are inadequate, their purpose is to study creative potential and the proposed tasks usually comprise different types of puzzles which do not take into account the context of field creativity (Plucker \& Makel, 2010; Plucker \& Runco, 1998).

Due to the concerns of participants and the lack of appropriate measurement instruments, researchers have usually chosen qualitative methods. This choice allows one to explore some topics in greater depth, but consequently makes it difficult to generalise the information obtained (Simonton, 2014a). It also entails a mundane, but very important issue for the researcher-investor-the need to authorise the information obtained and often its interpretation. This may mean entering into an uncertain market which could pose a particular threat to investment. This is especially difficult when creators want to withdraw their consent at the point where approval is sought for the final report. In such a situation, the researcher may experience a crash and lose all of his invested assets. This is a risk, especially in the light of scheduled projects financed from external sources, and could be a serious argument for discouraging investment in the elite trend of research on creativity. 
The researcher of eminent creativity who decides to use existing sources encounters limitations of a different nature: a lack of general information limited to existing sources (Cox, 1926; Simonton, 1990;), and very often secondary data, anecdotal features, or interpretations written by biographers, historians and other researchers. In analyses of eminent living artists, and also of their environment and works, existing data is rarely used (Karwowski \& Lebuda, 2013, 2014).

\section{Challenge 4. Publication of the Study Results}

If the researcher has overcome the above problems and has secured acceptance for the prepared analyses, it is time of selling, to present the results to a wider audience. What are the chances to sell at a profit? For this purpose, fundamental and technical analyses may be helpful (Sternberg \& Lubart, 1996)-an overview of how important the information obtained is, and to what extent the market is saturated with this type of product. Among researchers working on eminent creativity there is a demand for more diverse studies realized within different subfields of psychology (Simonton, 2009). In response to my question: Are studies of eminent creativity lacking any specific type of research? If yes, what type of research is still needed? Dean Simonton, expert on historiometry, answered: 'We can never have too much research on this topic! We need more research on the nature-nurture issue, on the mad-genius controversy, etc. etc.'

Many of the topics from the psychology of eminent creativity seem to be fully covered (e.g. the relationship of mental disorders and affective disorders with creative activities), but many of them are superficial in nature and one can easily point to numerous theoretical, methodological, analytical and interpretational simplifications (Piffer, 2012; Simonton, 2014b). In this area of research there is a need to not only find new, untouched topics, but to also to re-analyse previously obtained results and revise existing conclusions.

In order to estimate what the market of eminent creativity research looks like, I conducted a simple technical analysis. I analysed a number of scientific articles published in 2013 in four key creativity journals: Creativity Research Journal (CRJ ) (four issues, 42 articles in total), Psychology of Aesthetics, Creativity, and the Arts (PACA) (four issues, 37 articles), The Journal of Creative Behavior (JCB) (four issues, 15 articles) and Thinking Skills and Creativity (TSC) (three issues, 41 articles), (see Beghetto, Plucker \& MaKinster, 2001; Feist \& Runco, 1993; Sternberg \& Lubart, 1999, 2010). I included 135 articles in the analysis; excluding short research notes (CRJ), introductions from editors $(P A C A)$, conclusions of special editions $(J C B)$ and book reviews (TSC). I classified the articles based on the 4C classification (Kaufman \& Beghetto, 2009) and coded articles devoted to potential creativity (mini- and little-c) together; separate categories were in- 
cluded for articles devoted to professional creativity and on eminent creativity. I based classification of the texts mainly on the content of the abstract, keywords, and in the case of empirical texts on the research methodology. Among the 135 articles from all four journals, only two (1.5\%) (Boerner \& Jobst, 2013; Swami, 2013) dealt with eminent creativity, and 22 (16.0\%) with professional creativity (12 PACA; 7 CRJ; 2 TSC; 1 JCB), for example: Chan, Hui, Cheng and Ng, (2013); Karpova, Marcketti and Kamm, (2013); Nęcka and Hlawacz, (2013); Simoens and Tervaniemi, (2013). Among articles devoted to professional creativity: 16 (72.8\%) were based on quantitative analyses, three (13.6\%) on qualitative analyses and three (13.6\%) represented theoretical considerations; both articles on eminent creativity were supported with results from quantitative analyses (see also Feist \& Runco, 1993).

The results do not lead to obvious conclusions. On the one hand, the small number of articles devoted to eminent creativity and the lack of qualitative research in this field could form a niche for researchers. On the other hand however, it may indicate saturation of the market, or specific editorial policy, rejecting articles on the subject (Plucker, Beghetto \& Dow, 2004, 1985; Plucker \& Beghetto, 2003) or those conducted within a specific research paradigm-in the end, psychobiographical studies are sometimes treated as quasiscientific, concerning individuals, not general regularities (Simonton, 2009).

\section{DISCUSSION AND CONCLUSION}

Over the past two years, I interviewed about 50 people involved professionally in creativity, whose works are socially recognised, at least in Poland. Unfortunately it is still too early to speak about profits, although in the context of parallel projects, I can already speak of tangible results: publications sold for a satisfactory price in the main journals of the field. It seems that for those researchers who are not yet tenured and do not merely want to be speculators (short-term players) in the study of eminent creativity, who are at the same time obliged comply with the applicable rules of professional advancement, it is necessary for an investment strategy of diversification of their investment portfolio-to get involved in more than one project or research topic.

Assuming that scientific work in particular research, is a creative task (Simonton, 2004), researchers can look at their past and future projects in the light of the investment theory of creativity (Sternberg \& Lubart, 1991, 1996) and assess current and considered projects in terms of the profitability of issues, topics and research methods undertaken. It seems that in the light of investment theory research on eminent creativity is associated with numerous challenges, requiring the investment of considerable resources, a high risk of failure and difficulties with the sale (publication), but with little competition. 
The reflections from the research experience presented here are ultimately an incentive to explore the topic in more depth (for example, to examine trends in publications on different levels of creativity in the space of a few or several decades, since 1950) rather than an indisputable argument in the discussion. But I hope that this text can be a stimulus for reflection within the metascience of creativity. Perhaps, it will be helpful to other researchers on the subject of eminent creativity. With those thoughts at the end, in anticipation of the boom, I can share the advice of Dean K. Simonton, who in response to the question:

"Do you have any tips for researchers who are beginning their work on eminent creativity? answered: 'There are many different approaches, such as psychometric, interview, and historiometric. Pick the one that fits you best, and go with it."

\section{REFERENCES}

Amabile, T. M. (1982). Social psychology of creativity: A consensual assessment technique. Journal of Personality and Social Psychology, 5, 997-1013.

Baer, J. (1998). The case for domain specificity in creativity. Creativity Research Journal, 11, 173-177. Baer, J. (2010). Is creativity domain specific? In J. C. Kaufman \& R. J. Sternberg (Eds.), The Cambridge handbook of creativity (pp. 321-341). New York: Cambridge University Press.

Baer, J. \& Kaufman, J. C. (2005). Bridging generality and specificity: The Amusement Park Theoretical (APT) Model of Creativity. Roeper Review, 27, 158-163.

Barsalou, L. M. \& Prinz, J. J. (1997). Mundane creativity in perceptual symbol systems. In

T. B. Ward, S. M. Smith \& J. Valid (Eds.), Creative thought: An investigation of conceptual structures and processes (pp. 267-307). Washington: American Psychological Association.

Beghetto, R. A., Plucker, J. A. \& MaKinster, J. G. (2001). Who studies creativity and how do we know? Creativity Research Journal, 3-4, 351-357.

Boden, M. (1996). Dimensions of Creativity. Cambridge-London: MIT Press.

Boerner, S. \& Jobst, J. (2013). Enjoying theater: The role of visitor's response to the performance. Psychology of Aesthetics, Creativity, and the Arts, 7, 391-408. doi: 10.1037/ a0034570

Chan, K., Hui, A., Cheng, S. T. \& Ng, Y. L. (2013). Perceptions of age and creativity in the workforce. Journal of Creativity Behavior, 47, 256-272. doi: 10.1002/jocb.34

Cox, C. (1926). Early mental traits of three hundred geniuses. Stanford, CA: Stanford University Press.

Cropley, D. H., Kaufman, J. C., Cropley, A. J. \& Runco, M. A. (2010). The dark side of creativity. New York: Cambridge University Press. 
Csikszentmihalyi, M. (1997). Creativity, flow and the psychology of discovery and invention. New York: Harper Collins.

Dweck, C. S. (2006). Mindset. New York: Random House.

Eysenck, E. J. (1995). Genius: The natural history of creativity. New York: Cambridge University Press.

Gardner, H. (1993). Creating Minds: An anatomy of creativity seen through the lives of Freud, Einstein, Picasso, Stravinsky, Eliot, Graham and Gandhi. New York: Basic Books.

Getzels, J. W. \& Csikszentmihalyi, M. (1969). Aesthetic opinion: An empirical study. The Public Opinion Quarterly, 33, 34-45.

Feist, G. J. \& Runco, M. A. (1993). Trends in the creativity literature: An analysis of research in the Journal of Creative Behavior (1967-1989). Creativity Research Journal, 6, 271-286.

Kahneman, D., Slovic, P. \& Tversky, A. (1982). Judgment under uncertainty: Heuristics and biases. New York: Cambridge University Press.

Karpova, E., Marcketti, S. \& Kamm, C. (2013). Fashion industry professionals' viewpoints on creative traits and strategies for creativity development. Thinking Skills and Creativity, 10, 159-167. doi: http://dx.doi.org/10.1016/j.tsc.2013.09.001

Karwowski, M. (2013). Creative mindsets: Measurement, correlates, consequences. Psychology of Aesthetics, Creativity, and the Arts, 8, 62-70. doi: 10.1037/a0034898

Karwowski, M. \& Lebuda, I. (2013). Extending climato-economic theory: When, how, and why it explains differences in nations' creativity. Behavioral and Brain Sciences, 36, 29 -31. doi: http://dx.doi.org/10.1017/S0140525X13000150

Karwowski, M. \& Lebuda, I. (2014). Digit ratio predicts eminence of Polish actors. Personality and Individual Differences, 64, 30-34. doi: http://dx.doi.org/10.1016/ j.paid.2014.02.014

Karwowski, M. \& Lebuda, I. (2015) Creative mindsets. Manuscript in preparation.

Karwowski, M. \& Lebuda, I. (2013). Tell me your name and I'll tell you how creative your work is: Author's name and gender as factors influencing assessment of product originality in four different domains. Creativity Research Journal, 25, 137-142. doi: $10.1080 / 10400419.2013 .752297$

Kasof, J. (1995). Explaining creativity: The attributional perspective. Creativity Research Journal, 8, 311-366.

Kaufman, J. C. (2009). Creativity 101. New York: Springer Publishing Company.

Kaufman, J. C. \& Beghetto, R. A. (2009). Beyond big and little: The Four C Model of Creativity. Review of General Psychology, 13, 1-12. 
McGonigal, A. (2010). Art, value and character. The Philosophical Quarterly, 240, 545-566. Mroz, B. (2008). Osobowosc wybitnych aktorow Polskich. Studium roznic miedzygeneracyjnych. [Personality of eminent Polish actors. Study of intergenerational differences]. Warszawa: Wydawnictwo Naukowe Scholar.

Necka, E. \& Hlawacz, T. (2013). Who has an artistic temperament? Relationships between creativity and temperament among artists and bank officers. Creativity Research Journal, 25, 182-188. doi: 10.1080/10400419.2013.783744

Niu, W. \& Sternberg, R. J. (2006). The philosophical roots of western and eastern conceptions of creativity. Journal of Theoretical and Philosophical Psychology, 26, 18-38.

Piffer, D. (2012). Can creativity be measured? An attempt to clarify the notion of creativity and general directions for future research. Thinking Skills and Creativity, 3, 258-264.

Plucker, J. \& Beghetto, R. (2003). Why not be creative when we enhance creativity? In J. H. Borland (Ed.), Rethinking gifted education (pp. 215-226). New York: Teachers College Press.

Plucker, J. A., Beghetto, R. A. \& Dow, G. (2004). Why isn't creativity more important to educational psychologists? Potential, pitfalls, and future directions in creativity research. Educational Psychologist, 39, 83-96.

Plucker, J. A. \& Makel, M. C. (2010). Assessment of creativity. In J. C. Kaufman \& R. J. Sternberg (Eds.), The Cambridge handbook of creativity (pp. 48-74). New York: Cambridge University Press.

Plucker, J. A. \& Runco, M. A. (1998). The death of creativity measurement has been greatly exaggerated: Current issues, recent advances, and future directions in creativity assessment. Roeper Review, 21, 36-40.

Richards, R. (1990). Everyday creativity, eminent creativity, and health. Creativity Research Journal, 3, 300-326.

Rubenson, D. I. \& Runco, M. A. (1992). The psychoeconomic approach to creativity. New Ideas in Psychology, 10, 131-147.

Rudowicz, E. (2003). Creativity and culture: Two way interaction. Scandinavian Journal of Educational Research, 3, 273-290.

Simoens, V. L. \& Tervaniemi, M. (2013). Musician-instrument relationship as a candidate index for professional well-being in musicians. Psychology of Aesthetics, Creativity, and the Arts, 7, 171-180. doi: 10.1037/a0030164

Simonton, D. K. (1984). Genius, creativity, and leadership: Historiometric inquiries. Cambridge, MA: Harvard University Press. 
Simonton, D. K. (1990). Psychology, science, and history: An introduction to historiometry. New Haven: Yale University Press.

Simonton, D. K. (1994). Greatness, who makes history and why. New York: Guilford Press.

Simonton, D. K. (2004). Creativity in science: Chance, logic, genius and zeitgeist. New York: Cambridge University Press.

Simonton, D. K. (2008). Scientific talent, training, and performance: Intellect, personality, and genetic endowment. Review of General Psychology, 12, 28-46.

Simonton, D. K. (2009). Genius 101. New York: Springer Publishing Company.

Simonton, D. K. (2010). Creativity in highly eminent individuals. In J. C. Kaufman \& R. J. Sternberg (Eds.), The Cambridge handbook of creativity (pp. 174-188). New York: Cambridge University Press.

Simonton, D. K. (2014a). Significant Samples-Not Significance Tests! The often overlooked solution to the replication problem. Psychology of Aesthetics, Creativity, and the Arts, 8, 11-12. doi: 10.1037/a0035849

Simonton, D. K. (2014b). More method in the mad-genius controversy: A historiometric study of 204 historic creators. Psychology of Aesthetics, Creativity, and the Arts, 8, 53-61. doi: 10.1037/a0035367

Stein, M. I. (1953). Creativity and culture. Journal of Psychology, 36, 311-322.

Sternberg, R. J. \& Lubart, T. I. (1991). An investment theory of creativity and its development. Human Development, 34, 1-31.

Sternberg, J. R. \& Lubart, T. I. (1996). Investing in creativity. American Psychologist, 7, 677-688.

Sternberg, R. J. \& Lubart, T. I. (1999). The concept of creativity: Prospects and paradigms. In R. J. Sternberg (Ed.), Handbook of Creativity (pp. 3-16). London: Cambridge University Press.

Sternberg, J. R. \&, Lubart, T. I. (2010). The concept of creativity: Prospects and paradigms. In R. J. Sternberg (Ed.), Handbook of Creativity (pp. 3-15). New York: Cambridge University Press.

Swami, V. (2013). Context matters: Investigating the impact of contextual information on aesthetic appreciation of paintings by Max Ernst and Pablo Picasso. Psychology of Aesthetics, Creativity, and the Arts, 7, 285-295. doi: 10.1037/a0030965

Corresponding author at: Izabela Lebuda, Department of Educational Sciences, Academy of Special Education, 40 Szczesliwicka St., 02-353 Warsaw, Poland.

E-mail: izalebuda@gmail.com 